\title{
The pre-loaded set-screw in InterTAN nail: should it be tightened or not tightened in pertrochanteric hip fractures
}

\section{Shou-Chao Du}

Shanghai Yangpu District Central Hospital

Xiu-Hui Wang

Shanghai Pudong New District Zhoupu Hospital

Shi-Min Chang ( $\sim$ shiminchang11@aliyun.com)

Shanghai Yangpu District Central Hospital

Technical note

Keywords: Pertrochanteric fracture; Cephalomedullary nail; InterTan nail; Setscrew; Fracture non-union

Posted Date: August 13th, 2020

DOI: https://doi.org/10.21203/rs.3.rs-56746/v1

License: () (1) This work is licensed under a Creative Commons Attribution 4.0 International License. Read Full License 


\section{Abstract}

Background: InterTan is a specific type of cephalomedullary nail with a twin interlocking de-rotation and compression screw, which has inherent ability of anti-rotation. Whether to tighten or not to tighten the preloaded setscrew in InterTan nail is controversial in clinical practice.

Methods: We retrospectively collected four nonunion cases of unstable pertrochanteric femur fractures (AO/OTA-31A2), all were treated with InterTan nail and the preloaded setscrew was tightened in order to prevent further sliding and femoral neck shortening.

Results: After 6 months to 2 years follow-up, the fractures showed nonunion in radiography and the patients complained slight to middle degrees of pain, and had to use walking stick assistant in activities of daily life. Tightening the pre-loaded setscrew to prevent postoperative secondary sliding as static constructs might keep the femoral neck length, but lose the opportunity of telescoping for fracture impaction, and take the risk of healing complications, such as fracture nonunion, femoral head cutout or nail breakage.

Conclusions: As the harm outweighs benefit, we advocate the preloaded setscrew in InterTan nail should not be tightened in pertrochanteric hip fractures (AO/OTA-31A1 and A2).

\section{Background}

Per/inter-trochanteric hip fractures are predominantly treated by fixed-angle sliding implants, such as extramedullary side-plates or intramedullary nails [1, 2]. The head-neck fragment is fixed by lag screw or helical blade, and connected to the femoral shaft. After internal fixation, it is important for the head-neck to avoid rotation, but permit secondary sliding. The movement of the head-neck fragment is mostly guided to slide in an axial direction along the implant (helical blade or lag screw) to the lateral side (telescoping).

A set-screw is also called a grub screw. It has no head and is typically used in a nail through tightening or loosening with a hex key to prevent rotation of the lag screw (e.g. in gamma-3 nail) or the helical blade (e.g. in trochanteric femoral nail, TFN), but preserving the ability of sliding to lateral side for dynamic bone compression at the fracture site to enhance fracture healing [3].

InterTan is a new type of cephalomedullary nail with a twin interlocking de-rotation and compression screw. As the two interlocking screws $(11.0 \mathrm{~mm}$ lag screw and $7.0 \mathrm{~mm}$ worm screw respectively) integrated together and works as a whole unit, it has the inherent ability of antirotation both in the oblique connection hole of the nail and in the bone of the femoral head [4]. However, there is a pre-loaded set-screw in InterTan nail. Locking the setscrew is optional, as stated in the manufacturer's guidance. The indication for its tightening is to prevent excessive lateral side sliding, if the operative surgeon thinks it is necessary. However, as every coin has its two sides, tightening the setscrew is like a double-edged sword. One must balance the pros and cons of prevention of head-neck telescoping.

\section{Methods}

From January 2016 to December 2018, we retrospectively collected four nonunion cases of unstable pertrochanteric femur fractures (AO/OTA-31A2), all were treated with InterTan nail and the preloaded setscrew was tightened in order to prevent further sliding and femoral neck shortening.

\section{Results}

After 6 months to 2 years follow-up, we collected 4 cases of non-unions in pertrochanteric hip fractures (AO/OTA 31A1 and A2) treated by InterTan nail (Table 1 and Figs. 1-2). All the setscrews were tightened and locked in these 4 cases. There were 2 females and 2 males, with an average age of 62 years (range 50-74), and follow-up of at least 6 months. The fractures showed nonunion in radiography and the patients complained slight to middle degrees of pain, and had to use walking stick assistant in activities of daily life. 
Table 1

Patients data of pertrochanteric fracture nonunion after InterTan nailing with setscrew tightened and locked

\begin{tabular}{|c|c|c|c|c|c|c|c|c|c|c|}
\hline case & Age/sex & $\begin{array}{l}\text { Injury } \\
\text { mechanism }\end{array}$ & $\begin{array}{l}\text { AO/OTA } \\
\text { classification }\end{array}$ & $\begin{array}{l}\text { Fracture } \\
\text { reduction } \\
\text { quality }\end{array}$ & $\begin{array}{l}\text { Fixation } \\
\text { with } \\
\text { short } \\
\text { InterTan }\end{array}$ & $\begin{array}{l}\text { Beginning } \\
\text { of } \\
\text { standing } \\
\text { and } \\
\text { Weight- } \\
\text { bearing }\end{array}$ & $\begin{array}{l}\text { Non- } \\
\text { union } \\
\text { follow- } \\
\text { up } \\
\text { period }\end{array}$ & $\begin{array}{l}\text { Assistance } \\
\text { in } \\
\text { activities } \\
\text { of daily } \\
\text { life }\end{array}$ & $\begin{array}{l}\text { Pain } \\
\text { score } \\
\text { in } \\
\text { VAS } \\
\text { in } \\
\text { daily } \\
\text { life }\end{array}$ & $\begin{array}{l}\text { Revision } \\
\text { surgery }\end{array}$ \\
\hline 1 & $\begin{array}{l}74 / \\
\text { female }\end{array}$ & $\begin{array}{l}\text { Fall of } \\
\text { standing }\end{array}$ & $31 \mathrm{~A} 2.2$ & good & $\begin{array}{l}\text { Setscrew } \\
\text { tightened }\end{array}$ & 1 month & $\begin{array}{l}10 \\
\text { months }\end{array}$ & $\begin{array}{l}\text { Walking } \\
\text { stick }\end{array}$ & 4 & $\begin{array}{l}\text { Reverse } \\
\text { LISS }\end{array}$ \\
\hline 2 & $\begin{array}{l}73 / \\
\text { male }\end{array}$ & $\begin{array}{l}\text { Pedestrian } \\
\text { accident }\end{array}$ & $31 \mathrm{~A} 2.1$ & acceptable & $\begin{array}{l}\text { Setscrew } \\
\text { tightened }\end{array}$ & 1 month & 2 years & $\begin{array}{l}\text { Walking } \\
\text { stick }\end{array}$ & 3 & $\begin{array}{l}\text { Bipolar } \\
\text { femoral } \\
\text { head } \\
\text { with } \\
\text { long } \\
\text { stem }\end{array}$ \\
\hline 3 & $\begin{array}{l}72 \text { / } \\
\text { female }\end{array}$ & $\begin{array}{l}\text { Fall of } \\
\text { standing }\end{array}$ & $31 \mathrm{~A} 2.2$ & good & $\begin{array}{l}\text { Setscrew } \\
\text { tightened }\end{array}$ & 1 month & $\begin{array}{l}6 \\
\text { months }\end{array}$ & $\begin{array}{l}\text { Walking } \\
\text { stick }\end{array}$ & 2 & Not yet \\
\hline 4 & $\begin{array}{l}50 / \\
\text { male }\end{array}$ & $\begin{array}{l}\text { Traffic } \\
\text { accident }\end{array}$ & 31A2.1 & acceptable & $\begin{array}{l}\text { Setscrew } \\
\text { tightened }\end{array}$ & 1 month & 2 years & $\begin{array}{l}\text { Walking } \\
\text { stick }\end{array}$ & 3 & PFLP \\
\hline
\end{tabular}

VAS: visual analogue scale; LISS: limited invasive stabilization system; PFLP: proximal femoral locking plate

\section{Case Reports}

\section{Illustrative Case 1}

A 74-year-old female patient suffered an AO/OTA 31A2.2 pertrochanteric hip fracture due to fall of standing. After pre-operative examination and preparation, she was operated with closed reduction and InterTan nail fixation on fracture table. Instrument fracture reduction was performed for anterior cortex apposition. The fracture reduction quality was good according to Baumgaertner's [5], as well as Chang's [6] criteria. The operative procedure was as usual. The lower worm screw was turned to grasp the upper lag screw, and to compress the fracture gap by $5 \mathrm{~mm}$. The pre-loaded setscrew was tightened and locked that intended to maintain the femoral neck length.

The patient was followed up regularly and allowed weight-bearing in 1month. Unfortunately, the fracture was not healed in 4 months. As the patient's bone quality was good and the instrument was strong, no lag screw cut-out nor nail breakage was occurred yet in 7 months. Coronal CT reconstruction showed non-union. Sclerotic change was seen at the fracture site (Fig. 1). As there was pain in activities of daily life, the patient finally underwent revision fixation by reverse LISS plate in 10 months.

There were some shortcomings of the operation. On top of static locking, the proximal bone fragment ( superolateral neck cortex) stopped at the nail, i.e., the hard cortex of the neck at the superolateral portion might obstruct further sliding of the head-neck fragment, even with the set screw not tightened, there might be some gap in the lower portion. The gap in the medial calcar was caused by "open effect" or "open deformity" during the insertion of the thick proximal nail. A more medial shift and reaming of the entry portal would probably solve the problem.

Figure 1. AP view of a pertrochanteric hip fracture (AO/OTA-31A2.2) in a 74-year-old female (a). During operation with closed reduction and InterTan nail fixation, percutaneous instrument was applied for medial cortex reduction (b). Fluoroscopy after operation, the fracture reduction quality and implant position were good. Note the setscrew (red arrow) was tightened and locked to avoid head-neck sliding after operation ( $c$ and d). The fracture was not healed in 4 months (e). As the bone quality was good and the instrument was strong, no lag screw cutout nor nail broken occurred yet in 7 months. Coronal CT reconstruction showed non-union. Sclerotic change was seen at the fracture site (f).

\section{Illustrative case 2}

A 73-year-old male pertrochanteric fracture with AO/OTA-type 31A2.1 was treated by closed fracture reduction and InterTan nail fixation (Fig. 2). Radiography at 1 week after nailing showed head-neck varus mal-alignment, the lag screw was placed in the upper part of the femoral head, but the medial calcar contacted in smooth. The patient was allowed standing and weight-bearing in 1 month. He complained slight to moderate pain in activities of daily life. Two years later, the fracture was noted non-union, as demonstrated by a clear medial cortex gap between head-neck and shaft. Furthermore, the nail had a movement of sway in the coronal plane as the radiography showed a 
sclerotic line around the nail. Bone enlargement was observed at the distal interlocking screw as stress reaction due to load sharing that transmitted from the screw.

Figure 2. AP view of a pertrochanteric hip fracture (AO/OTA-31A2.1) in a 73-year-old male (a). Radiography at 1 week after InterTan nailing showed head-neck varus mal-alignment but the medial calcar contacted in smooth (b). Two years later, the fracture was not healed as demonstrated a clear medial cortex gap (yellow arrow) between head-neck and shaft. The nail swayed in coronal plane as there showed a sclerotic line around the nail. Bone at the distal interlocking screw were enlarged (red arrow) as it sharing load from the screw (c).

The third case was a 72-year-old female with 31A2.2 pertrochanteric hip fracture. Radiographs at 6 month follow-up showed fracture nonunion after InterTan fixation. The fourth case was a 50-year-old male with 31A2.1 pertrochanteric fracture, which was fixed by InterTan nail. The AP and lateral radiographs showed the fracture was not healed till 1.5 years.

\section{Discussion}

Operative treatment is the management of choice for most trochanteric hip fractures in current practice [7]. Key decisions for the surgeon are fracture reduction, choice of implant, and implant positioning. To date, the dynamic mechanism instruments of sliding hip screw/blade clearly indicates that this type of implant has a lower fracture-healing complication rate. InterTan is a new type of cephalomedullary nail with a pre-loaded set-screw. As stated in the manufacturer's guidance, using or not using the pre-loaded set-screw is optional. The resulting fixation with setscrew tightening and locking will be static with no opportunity for any collapse to occur at the fracture site. We want to argue this indication and advocate that the set-screw in InterTan nail should be seldom tightened in pertrochanteric fractures. The reasons are as follows:

Firstly, it is difficult to achieve an exact anatomic reduction in pertrochanteric fractures by closed maneuver and intraoperative fluoroscopic control. According to our investigation, a smooth cortex contact viewed in fluoroscopy is called neutral cortical apposition, which may actually contain three sub-conditions:(1)an exact real anatomic smooth cortex-to-cortex position, (2) a slightly positive extra-medullary buttressed position, or (3) a slightly intra-medullary negative position [8]. However, as the image resolution of intra-operative fluoroscopy is limited, 2-mm cortical steps may not be identifiable. Therefore, those three sub-conditions are generally not able to be clearly distinguished, i.e. the so called anatomic reduction in fluoroscopy may not be really anatomic.

Secondly,though the head-neck fragment can be compressed primarily by the surgeon during operation through tightening the smaller compression screw (the lower worm screw). However, bone resorption does occur during fracture healing. There may be a gap at the fracture site, which may result in no cortical contact between the head-neck and the shaft. A gap between the medial calcar cortices may lead to a longer healing time, a delayed healing or even a non-healing, which is a risk factor for complications and treatment failure.

Thirdly,in the post-operative period, during the contraction of the muscles or the patient's weight bearing stage, continuous dynamic pressure is applied to the fracture site. The fracture gap can be eliminated by secondary sliding through impaction, which promotes the close contact of the head-neck fragment with the femoral shaft and achieve a secondary stability. Sliding provides an opportunity for the fracture site to re-adjust and re-sit firmly with each other, promote fracture consolidation and healing. In other words, postoperative secondary sliding can make up some technical shortcomings during the operation.

Fourthly, the aim of tightening and locking the set-screw is to prevent over-sliding and maintain the length of femoral neck. In our opinion, obtaining anteromedial cortex support through fracture reduction technique is a more safe and effective biomechanical approach to prevent excessive sliding. By direct cortical contact, the anteromedial cortex of the femoral shaft can resist the head-neck fragment from further sliding laterally, keep an almost normal neck length and neck-shaft angle [9]. The cortical contact permits limited and controlled telescope, which has both mechanical (load sharing) and biological (healing) advantages [10].

Therefore, tightening the setscrew to prevent sliding as static constructs may keep a normal femoral neck length, but lose the possibility to make up technical shortcomings, and take the risk of fracture healing complications; on the other hand, not tightening the setscrew to allow head-neck dynamic sliding will promote fracture healing but take the risk of femoral neck shortening. Of two evils choose the lesser. Now, we prefer to accept a limited shortening femoral neck, rather than the risk of fracture nonunion, femoral head cutout, or implant breakage, which need further revision surgery. In the treatment of two-part intertrochanteric femur fractures (2018-A0/0TA: 31A1.2), Ricci et al.[11] stated that they did not use set screws in the InterTan group, and if it was used in the TFN group (the head-neck can be fixed with either a lag screw or a helical blade), up to approximately $10 \mathrm{~mm}$ dynamic sliding was allowed.

There are some common features of these 4 cases. Firstly, although some technical deficiencies maybe exist, the overall fracture reduction quality and implant placement position are good or acceptable. Secondly, the set-screw is tightened and locked and no head-neck sliding 
happened after operation. The InterTan nail becomes a static implant. Thirdly, patient's bone quality is relatively good, and can provide enough grasp with the screws to avoid cutout. Fourthly, the nail is thicker and stronger and there is no nail breakage. With the assistance of a stick, all patients can walk and care themselves in daily life, but with persistent pain in some degree. And lastly, the reason for delayed union or non-union is mostly attributed to the static fixation mechanism.

\section{Conclusions}

To maintain femoral neck length in practice, we advocate that surgeons pay greater emphasis on the anteromedial cortex reduction quality to get a cortical support apposition [12,13]. Permission of limited telescoping after surgery provides controlled fracture impaction to a favorable secondary stability and fracture healing in per/inter-trochanteric fractures. For subtrochanteric fractures, in the other hand, as no sliding occurred between head-neck and the shaft, there is no difference whether the set-screw is tightened or not tightened [14].

\section{List Of Abbreviations}

AO/OTA: Arbeitsgemeinschaftfür Osteosynthesefragen / Orthopaedic Trauma Association

TFN: trochanteric femoral nail

VAS: visual analogue scale

LISS: limited invasive stabilization system

PFLP: proximal femoral locking

\section{Declarations}

\section{Ethics approval and consent to participate}

The study was approved by Institutional Review Board of Yangpu Hospital, Tongji University (No. 2017ZRKX-013). Written informed consent was obtained from all patients.

\section{Consent for publication}

Not applicable

\section{Availability of data and material}

All data used and analyzed during this study are available from the corresponding author on reasonable request.

\section{Competing interests}

The authors declare that they have no competing interests.

\section{Funding}

The study was supported by National Natural Science Foundation of China (NSFC, No. 81772323) and The Featured Clinical Discipline Project of Shanghai Pudong New District (PWYts 2018-02).

\section{Authors' contributions}

Shou-Chao Du (SCD) and Shi-Min Chang (SMC) performed the study design, and contributed to the collection of the cases. SCD and XiuHui Wang $(\mathrm{XHW})$ analyzed the results, and contributed equally to the study. All authors reviewed and approved the final submitted version.

\section{Acknowledgements}

Not applicable

\section{References}


1. Turesson E, Ivarsson K, Thorngren KG, Hommel A. Hip fractures - Treatment and functional outcome. The development over 25 years. Injury. 2018;49(12):2209-2215. doi:10.1016/j.injury.2018.10.010

2. Hoffmann MF, Khoriaty JD, Sietsema DL, Jones CB. Outcome of Intramedullary Nailing Treatment for Intertrochanteric Femoral Fractures. J Orthop Surg Res. 2019;14(1):360. doi: 10.1186/s13018-019-1431-3.

3. Nherera L, Trueman P, Horner A, Watson T, Johnstone AJ. Comparison of a twin interlocking derotation and compression screw cephalomedullary nail (InterTAN) with a single screw derotation cephalomedullary nail (proximal femoral nail antirotation): a systematic review and meta-analysis for intertrochanteric fractures.J Orthop Surg Res. 2018;13(1):46. doi: 10.1186/s13018-018-0749-6

4. İmerci A, Aydogan NH, Tosun K. A comparison of the InterTan nail and proximal femoral nail antirotation in the treatment of reverse intertrochanteric femoral fractures. Acta Orthop Belg. 2018;84(2):123-131.

5. Baumgaertner MR, Curtin SL, Lindskog DM, Keggi JM. The value of the tip-apex distance in predicting failure of fixation of peritrochanteric fractures of the hip. J Bone Joint Surg Am. 1995;77(7):1058-1064. doi:10.2106/00004623-199507000-00012

6. Chang SM, Zhang YQ, Ma Z, Li Q, Dargel J, Eysel P. Fracture reduction with positive medial cortical support: a key element in stability reconstruction for the unstable pertrochanteric hip fractures. Arch Orthop Trauma Surg. 2015;135(6):811-818. doi:10.1007/s00402015-2206-X

7. Parker M. Trochanteric hip fractures. In: Tornetta P III, Ricci WM, Ostrum RF, McQueen MM, McKee MD, Court-Brown CM, editors. Rockwood and Green's Fractures in Adults. 9th ed. Wolters Kluwer; 2019. p. 2285-2317.

8. Mao W, Ni H, Li L, He Y, Chen X, Tang H, Dong Y. Comparison of Baumgaertner and Chang reduction quality criteria for the assessment of trochanteric fractures. Bone Joint Res. 2019;8(10):502-508. doi:10.1302/2046-3758.810.BJR-2019-0032.R1

9. Chang SM, Zhang YQ, Du SC, Ma Z, Hu SJ, Yao XZ, Xiong WF. Anteromedial cortical support reduction in unstable pertrochanteric fractures: a comparison of intra-operative fluoroscopy and post-operative three dimensional computerised tomography reconstruction. Int Orthop. 2018;42(1):183-189. doi: 10.1007/s00264-017-3623-y

10. Xiong WF, Hu SJ, Chang SM. Avoiding over-telescoping to improve outcomes in cephalomedullary nailing. Injury. 2017;48(11):26082609. doi: 10.1016/j.injury.2017.09.011

11. Ricci MJ, McAndrew CM, Miller AN, Kamath G, Ricci WM. Are two-part intertrochanteric femur fractures stable and does stability depend on fixation method? J Orthop Trauma. 2019;33(9):428-431. doi: 10.1097/BOT.0000000000001509

12. Chang SM, Hou ZY, Hu SJ, Du SC. Intertrochanteric Femur Fracture Treatment in Asia: what we know and what the world can learn. Orthop Clin North Am, 2020; 51(2): 189-205. doi: 10.1016/j.ocl.2019.11.011

13. Zhang W, Antony Xavier RP, Decruz J, Chen YD, Park DH. Risk factors for mechanical failure of intertrochanteric fractures after fixation with proximal femoral nail antirotation (PFNA II): a study in a Southeast Asian population. Arch Orthop Trauma Surg. 2020. doi:10.1007/s00402-020-03399-2

14. Kasha S, Yalamanchili RK. Management of subtrochanteric fractures by nail osteosynthesis: a review of tips and tricks. Int Orthop. 2020; 44(4):645-653. doi: 10.1007/s00264-019-04404-z

\section{Figures}




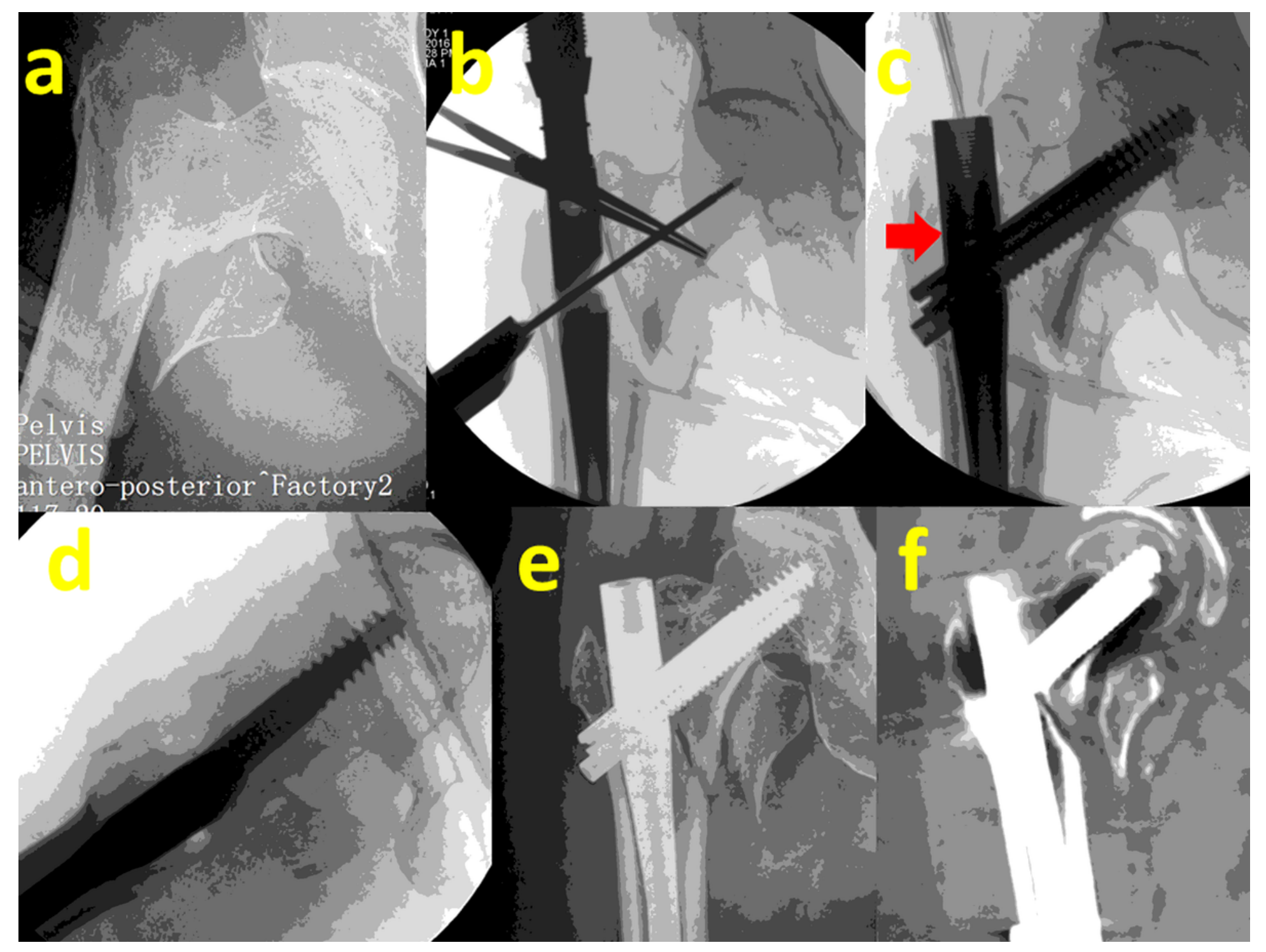

\section{Figure 1}

AP view of a pertrochanteric hip fracture (AO/OTA-31A2.2) in a 74-year-old female (a). During operation with closed reduction and InterTan nail fixation, percutaneous instrument was applied for medial cortex reduction (b). Fluoroscopy after operation, the fracture reduction quality and implant position were good. Note the setscrew (red arrow) was tightened and locked to avoid head-neck sliding after operation (c and d). The fracture was not healed in 4 months (e). As the bone quality was good and the instrument was strong, no lag screw cutout nor nail broken occurred yet in 7months. Coronal CT reconstruction showed non-union. Sclerotic change was seen at the fracture site (f). 


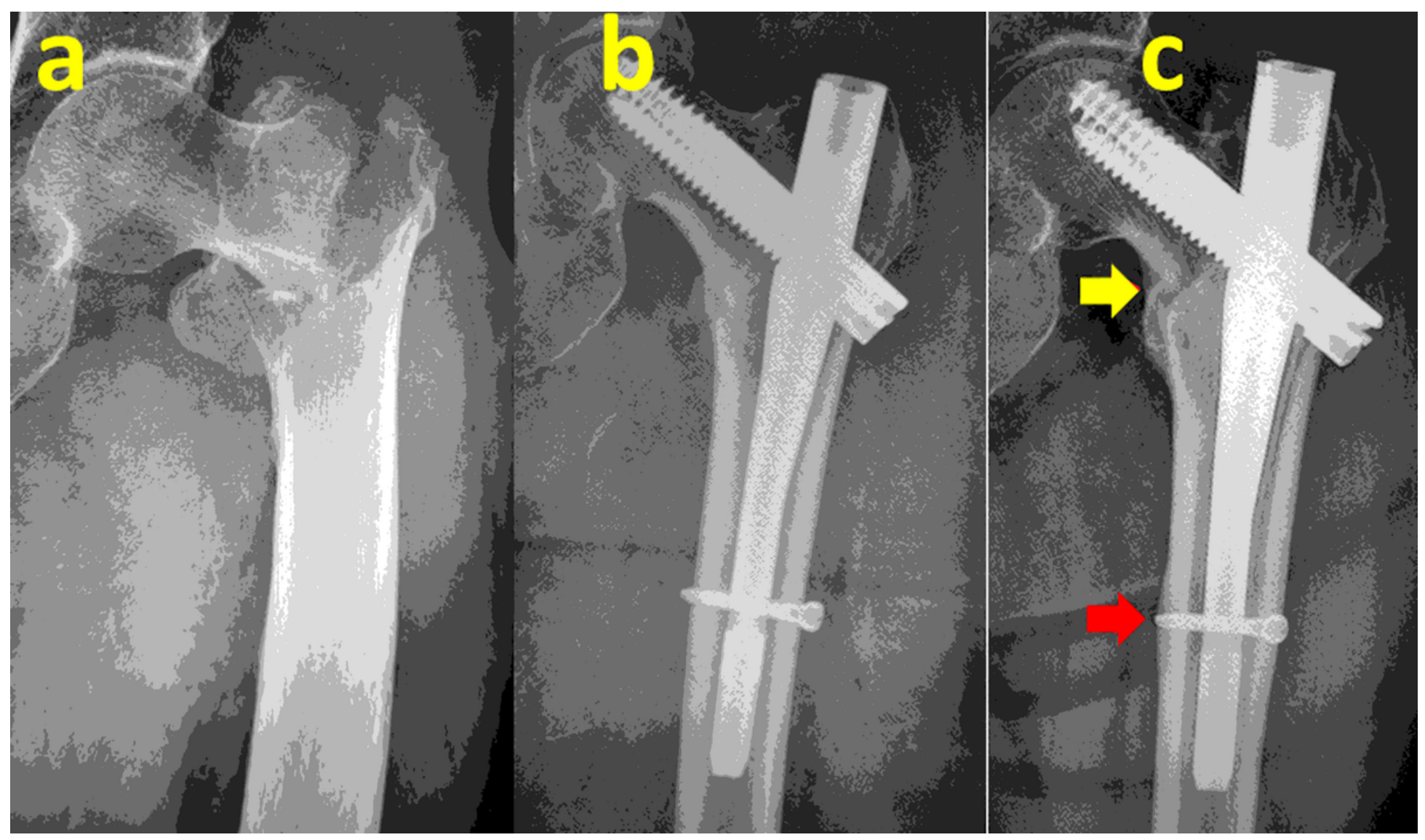

\section{Figure 2}

AP view of a pertrochanteric hip fracture (AO/OTA-31A2.1) in a 73-year-old male (a). Radiography at 1 week after InterTan nailing showed head-neck varus mal-alignment but the medial calcar contacted in smooth (b). Two years later, the fracture was not healed as demonstrated a clear medial cortex gap (yellow arrow) between head-neck and shaft. The nail swayed in coronal plane as there showed a sclerotic line around the nail. Bone at the distal interlocking screw were enlarged (red arrow) as it sharing load from the screw (c). 